\title{
Enterprise application integration for high school students using blended learning system
}

\author{
Muharman Lubis ${ }^{1 \mathrm{a}}$, Rahmat Fauzi $^{1}$ and Arif Ridho Lubis ${ }^{2}$ \\ ${ }^{1}$ School of Industrial Engineerin, Telkom University, Bandung, Indonesia \\ ${ }^{2}$ Department of Computer Engineering and Informatics, Politeknik Negeri Medan, Indonesia
}

\begin{abstract}
Education has purposes to improve quality of human resources and to develop readiness to look at future. It also play critical role to reduce ignorance, recognize the potency and shape the behavior in the community. There are two types well-know of education in Indonesia, which are formal (kindergarten, elementary, junior high, senior high and university) and non-formal (computer courses, English lessons, tutoring session, vocational training and professional certification). Of course, people will go to formal education to obtain graduation degree for the necessity of finding job and position in the market. But, some people tend to seek alternative to provide adequate education for their future. It hinted certain problems have been resided in the current educational model, which focus on face to face approach. Along with the rising of IT in the era of Industry 4.0 in every aspect of daily life, people learn mostly every subject through Internet without considering much on its credibility. Thus, this paper explore the possibility of using hybrid method, which is known for blended learning to be implemented in nonformal education to help facilitate the public on information availability and develop mastery-based presentation to improve the understanding of student efficiently.
\end{abstract}

\section{Introduction}

The current educational system, which adopted by many countries has shortcomings such as failing to meet the individual needs for sufficient ratio between students and teachers in teaching learning system, difficult to provide active engagement to subject material in the class, concern only to intellectual quotient from student by excluding any sort assessment to others quotients (emotional, spiritual, ecological, etc.) and serving the students' differences in term of resources, performances and capabilities [1, 2]. On the other hand, eLearning approach come to the picture as if to be the solution to solve the problem, while in reality, there are others problems caused by the implementation such as limited bandwidth and quota from student to access the system, evaluation and assessment control for grading, the high rate of drop out per subject and there is lack of interactivity between student and teachers [3-5]. This new environment approach combines the positive

\footnotetext{
a Corresponding author: muharmanlubis@telkomuniveristy.ac.id
} 
approach of e-Learning and classical learning to overwhelm drawbacks of current mechanism of teaching learning.

At the end of the transformation process to be the leaders that dominate the market, successful industrial companies should engage with creative way in innovate the breakthrough, with physical products in essence, add digital interfaces and innovative services based on data. Collaborative digital activities will become the mainstream process whereby the clients and the suppliers create digital ecosystems of Industry 4.0. An effective $\mathrm{BL}$ environment is critical to ensure the pedagogical approaches with the collaborative use of the teaching and learning, in which online learning only focus on superficial technological adoption rather than conceptual change process while offline only focus on quantity over quality [26]. By developing BL application for private and non-formal education is always challenging, especially to convince providers to put their trust and teach them on mechanism to align with their learning curves and outcomes. Even though, it is challenges the status quo, it balance both approach as the resources used will be optimized and minimalized. Actually, there are several types of BL methods proposed to use in the environment such as Rotation, Competency, Flex, A la Carte, Skill-Driven, Attitude-Driven and Enriched Virtual Model [6]. In short, parallel with the growing use of IT and the changes of student behavior to be distracted, BL offers an active learning environment with flexibility in using resources and provide interferences to increase student participation and performance in learning outcome based. Thus, this study investigates the possibility to implement the application to maximize the benefits of BL in non-formal education as it has non-strict regulated industry compare to formal education.

\section{Literature review}

Blended Learning can be defined as learning in an educational context characterized by a deliberate collaboration between Internet-based and classroom-based interventions to support learning process [7]. Therefore, learning process is mostly influenced by various aspect such as learning techniques, technology, individual differences, students' background, perception, content delivery, course structure, ethical, resources and management [8]. However, academicians have broad concept of the motivation as a process, not as a product, which can be distinguished by the student's belief and behavior such as choice of activities and quality of engagement [9]. In addition, comprehensive research program has defined a learning strategy as the special thought that help student to understand, learn and maintain new information through meta-cognitive, cognitive, social mediation, self-regulatory and resource management strategies [10, 11]. Despite the advantages of BL, it has been shown that most students required more training on how to use application in teaching learning environment where some consider studying online to be difficult, annoying and boring [12]. The implementation of BL requires comprehensive strategy plan, good teacher, suitable tutor training and ongoing evaluation such as WEBLEI, HELAM, TAM, ELearning Framework or Rubric-based [13].

The disappointment of BL often related to the multimedia use, self-assessment test, access to digital literature and collaborative activities but course management, material used, teacher engagement and timely feedback have been perceived well [14]. Interestingly, $\mathrm{BL}$ has become increasingly popular for several reasons namely cost effective, raising awareness among students, suits different learning styles, offers flexibility and reduces student anxiety [15]. In addition, future studies should revolve around how to use class time most effectively, what types of active learning exercise promote effective learning rather than performance and the attempts to move beyond using lecture as a control $[16,17]$. In fact, the developmental process should be started in the early childhood, which is shaped by values, culture and experiences of families and communities, but driven by mentality and 
customs [18]. Therefore, it is necessary to increase the learning outcome of BL by applying constructivism and conversation theories such as discussing the relevant experience on particular topic [19]. When understanding the visualization, it is also necessary to provide some ideas and opinions for better enhancement, either through suggestion or recommendation in evaluating the system use in the environment $[11,20]$. However, the extent to which the enjoyment in the online environment was largely dependent on whether students found that the material have clarity in line with the applied courses [21].

\section{Research methodology}

This study uses action-based and case-based research method that consist of qualitative approach include interviews, focus groups and observations in Indonesia. The researchers asked a group of students to develop the application for non-formal education market using classic lifecycle to make it easier implementation and evaluation. To analyze the requirement, the team uses Unified Model Language (UML), which involves Use Case diagrams, Class diagrams, Activity diagrams, Sequence diagrams and Entity Relationship diagrams to represent the relationship between entities and characteristics. At the development stage, it uses PHP to allow integration of service with HTML for website and MySQL for DBMS. However, the developed innovation in the culture and climate of each institution must adapt to the dynamic conversation and interaction in the institution. There is no universal approach that ensures success, nor does success come rapidly, but rather is obtained through accumulated effort over years. Meanwhile, according to survey, there are primary advantages of BL selected by students related to the flexibility to be able to complete the task anywhere and any time, the convenience of not necessarily coming to campus as often and the benefits of the online components when job responsibilities and commitments make it difficult to attend classes [22].

\section{System development}

\subsection{Institutional goals alignment}

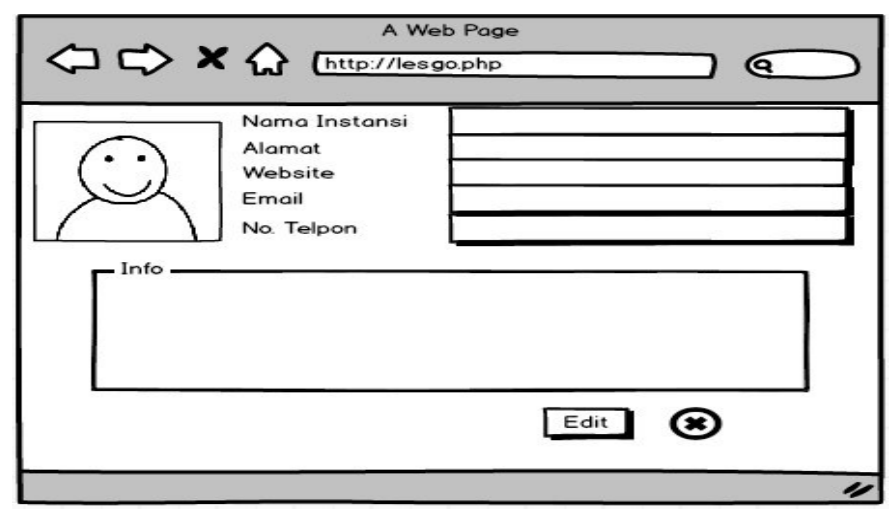

Fig. 1. Prototype of User Profile in Indonesian

Success is the achievement of specific goal in which an institution seeking to achieve it in the BL implementation. Thus, it should have the sense of purposes and the outcomes that is describe in the activity process such as division, unit, teacher or student goals. Thus, the decision makers should align the policy with the institution-centered goals to deliver the 
efficient use of classroom resources or expanding the reach of campus. The purpose of oriented goals can include better process through curriculum planning development and adoption of student centered of education practices such as greater convenience and flexibility, greater access, increased student academic success, or expanded information literacy. Some preliminary question also should be aligned with right strategy, such as why the institution engage in BL, what kind of advantages they want to achieve in short and long term, what type of course or program that will be offered use BL mechanism, how the infrastructure support the learning process and what level of investment should be prepared to gain return or profit [27]. The senior executives in the institution must play a critical role in formulating objectives for BL, together with the list of responsibilities to each relevant parties in teaching-learning process. However, the goals cannot be exclusive or even mandatory by the competence of superior leadership in topdown but also bottom-up approach. Over decades, several factors have been identified as discouraging academic staff from teaching use BL techniques such as inadequate support and training, not sufficient time for creating online materials, big fears of failure and lack of beliefs in technological value in education [23].

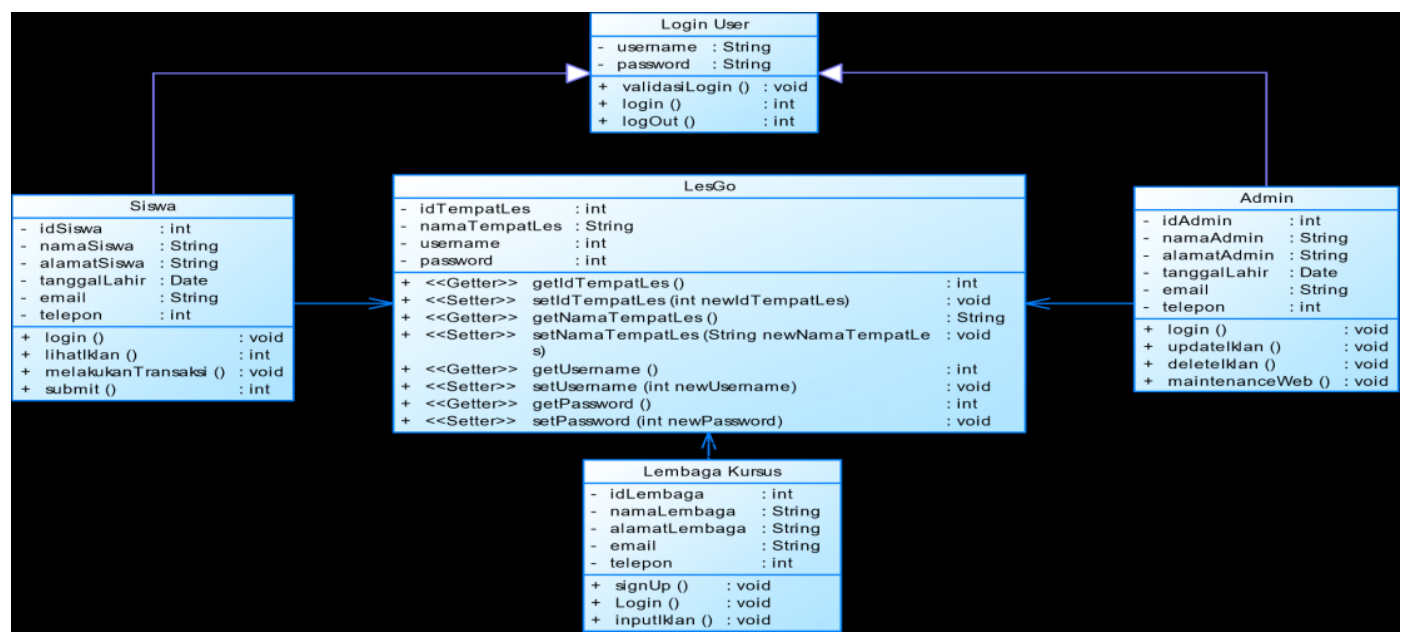

Fig. 2. Class diagram of LesGO application

\subsection{Proactive Policy Development}

Support for BL approach can take many forms such as direct phone support, voice mail, email, instant messaging, websites with documentation, video tutorial or drop-in centers. Alternatively, institutions can outsource support doamin to particular company to provide the service. In particular, BL requires the elements that are the same as other network services such as servers, load balancing, traffic management, network bandwidth and remote access. Those requirements are more stringent in terms of reliability and consistency compare to common network services, in which technical side should be well designed and properly monitored. The study also clearly shows that the mere application of technology and removing the physical classroom cannot immediately deliver the most ideal learning environment for foreign language learners or any subjects [24]. 

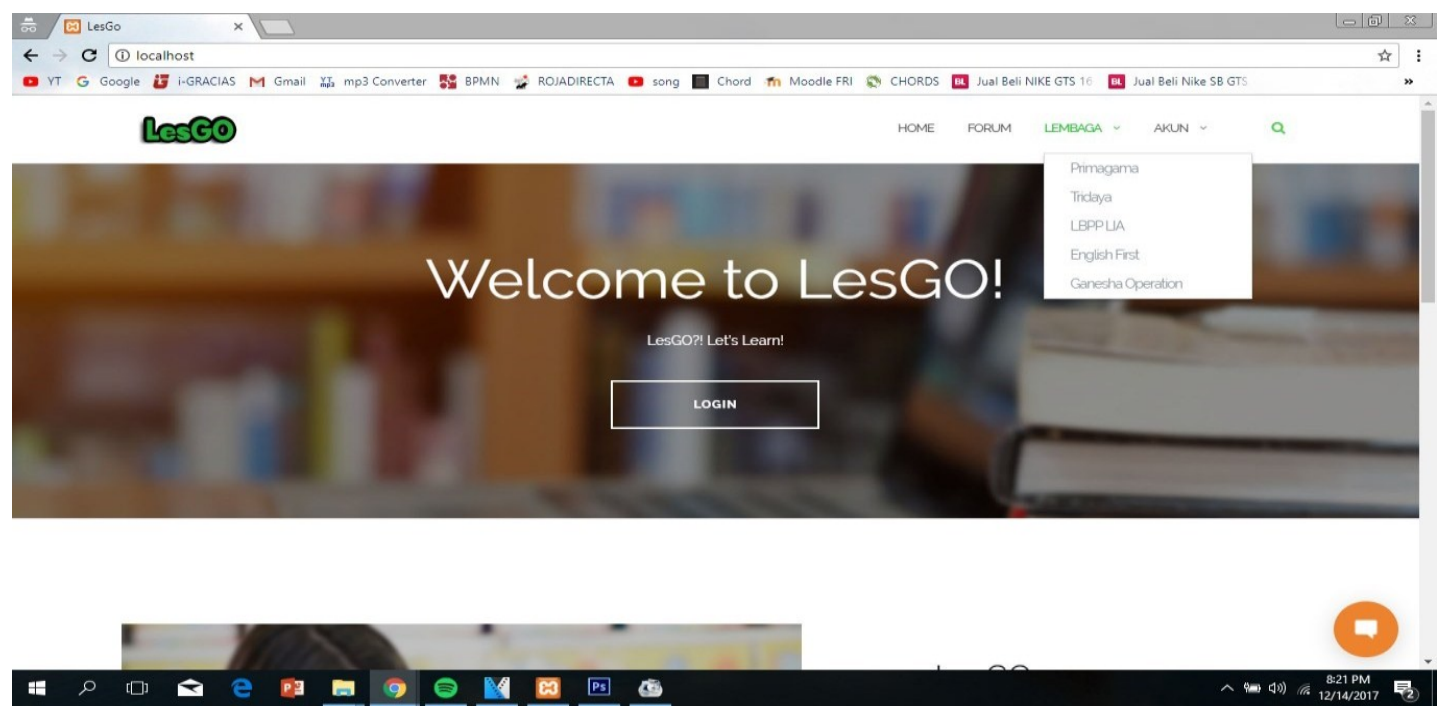

Fig. 3. Home page of LesGO application

Producing rich data sets over time brings an institution to pinpoint the effect of BL on students, staff and the teaching-learning process. Initially, the data gathering answer the questions such as does it run well or is it good method but later, the accumulated data will inform the institution to initiate continuous quality assessment to reach maturity model. Meanwhile, the changes to the existing course system, concentrate on BL approach, involving the improved topography of new generic skills or new cutting edge of technology like laser scanning or even enhanced skill-development activities, ubiquitous learning and balanced distribution of content among units, typically have been used to further alleviate the uniqueness of learning components over the others [25]. On the other hand, the ubiquity of the technology improved the efficiency and timeliness of content delivery in BL environment [26]. Organizations must understand how related products or customer services can serve as a vital basis for companies to identify customer opinions and the social, demographic and psychological factors that influence their decision making regarding the use of the connected product [27]. On the other hand, the interface is a communication mechanism between users and the system that can receive and provide information to users to support their activities until a solution is found, which presented in the figure 3 .

\section{Conclusion}

As BL traverses almost all sector of the learning teaching environment, it requires careful software development and policy implementation. Relevant executives should consider the modalities due to their impact on infrastructure requirements, course development and strategic planning. Therefore, employees should take the opportunity to raise their potential to accommodate the learning process to be more efficient. In addition, students should reconsider their concerns about the way of the educational system work and what is requires for competency. The modality of BL should be exercised in the consistent approach with its context and objective to maintain the organizational capacity. It also requires advanced support at all stages within organizational structure and student learning support mechanisms. Of course, they must be developed in acceptable condition of the institutional culture through adequate investment of resources. 


\section{Acknowledgement}

Thank you for the list of programmers from our students namely Bagus Aria Nugraha, Ramona Dwi Utari, Teguh Piganta Putra, Islamia Annida Sulistyo and Fitri Muthia Syifa.

\section{References}

1. K.L. Lalima, Dangwal. "Blended learning: an innovative approach." Universal Journal of Educational Research 5(1): 129-136. HRPUB (2017).

2. J. Kenney. "Adopting a blended learning approach: challenges encountered and lessons learned in an action research study." Journal of Asynchronous Learning Networks 15(1), 45-57, 2011. Online Learning Consortium.

3. P. Arinto. "Issues and challenges in open and distance e-Learning: perspective from the Philippines". International Review of Research in Open and Distributed Learning (17) 162-180. (2016).

4. H. Rana, Rajiv, M. Lal. "E-Learning: issues and challenges". International Journal of Computer Application 97(5), 20-24, (2014).

5. T. Capra. "Online education: promise and problems." Journal of Online Learning and Teaching 7(2), 288-293. Merlot (2011).

6. H. Staker, M.B. Horn. "Classifying K-12 blended learning”. 2012. Innosight Institute.

7. R. Boelens, S. Van Laer, B. De Wever, J. Elen. "Blended learning in adult education: towards a definition of blended learning". (2015).

8. P. Ramakrisnan, Yuraidza bt Yahya., M.N.H. Hasrol, A.A. Aziz. "Blended learning: a suitable framework for e-Learning in higher education." In Procedia Social and Behavioral Sciences 67, 513-526, 2012. Science Direct.

9. W. Liu, H. Yu, "Effectiveness study of English learning in blended learning environment." Theory and practice in language studies, 2(3), 524-530. Academy Publisher. (2012)

10. J.M. O’Malley, A.U. Chamot. "Learning strategies in second language acquisition". Cambridge University Press. (1990)

11. P.R. Pintrick, E. De Groot. "Motivational and self-regulated learning components of classroom academic performance." Journal of Educational Psychology, 82, 33-40, (1990).

12. G. Torrisi-Steele, S. Drew. "The literature landscape of blended learning in higher education: the need to better understanding of academic blended practice." International Journal for Academic Development 18(4), 371-383. Taylor \& Francis. (2013)

13. J. Bowyer, L. Chambers. "Evaluating blended learning: bringing the elements together." Research Matters 23. UCLES. (2017)

14. M. Zuvic-Butorac, N. Roncevic, D. Nemcanin, Z. Nebic. "Blended elearning in higher education: research on students' perspective." Issues in Informing Sciencce and Information Technology, 8, 409-429, (2011).

15. Y.M. Luna, S.A.Winters. "Why did you blend my learning? A comparison of student success in lecture and blended learning introduction to sociology courses". In Teaching Sociology, 45(2), 116130, SAGE (2017).

16. M. Lubis, M. Kartiwi and S. Zulhuda. "Privacy and personal data protection in electronic voting: factors and measures.” Telkomnika 15(1), pp. 512-521, (2017). 
17. M. Delucchi. "Measuring student learning in social statistics: a pretestposttest study of knowledge gain". Teaching Sociology 42(3), 231-239. SAGE. (2014)

18. S. Patrick, C. Sturgis. "Maximizing competency education and blended learning: insights from experts". CompetencyWorks Issue Brief. (2015)

19. A.M. Al-Huneidi, J. Schreurs. "Contructivism based blended learning in higher education." IJET 7(1), (2012)

20. M. Lubis, M. Kartiwi and S. Zulhuda."Current state of personal data protection in electronic voting: criteria and indicator for effective implementation." Telkomnika, 16(1), 290-301.

21. B. Kistow. "Blended learning in higher education: a study of a graduate school of business, Trinidad and Tobago." Carribean Teaching Scholar 1(2), 115-128, (2011).

22. M.J. Kintu, C. Zhu and E. Kagambe. "Blended learning effectiveness: the relationship between student characteristics, design features and outcomes." Int. J. of Educational Tech. in H. Education 14(7), (2017).

23. P. Moskal, C. Dziuban, J. Hartman. "Blended learning: a dangerous idea?" Internet and Higher Education 18, 15-23, (2013).

24. L.M. Jeffrey, A. Higgins. "Blended learning: how teachers balance the blend of online and classroom components.” J. of IT Education: Research, 13, 121-140, (2014).

25. A. El-Mowafy, M. Kuhn and T. Snow. "Blended learning in higher education: current and future challenges in surveying education." Issues in Educational Research, 23(2), 132-150, (2013).

26. F.Z. Azizan. "Blended learning in higher education institution in Malaysia." Proc. Of Regional Conf. on Knowledge Integration in ICT. 454-466. (2010)

27. V. Roblek, M. Mesko and A. Krapez. "A Complex view of industry 4.0" Sage Open, pp. 1-11. (April-June 2016) 